\title{
PROGRAMA DE ASSISTÊNCIA ESTUDANTIL PERMANÊNCIA 2015: APRESENTAÇÕES E REFLEXÕES
}

\author{
Ellana Barros Pinheiro ${ }^{1}$
}

Resumo: A partir da década de 80, a questão da permanência dos universitários passou a ser debatida com mais efervescência, pois, entendida como direito social baseado no Art. $6^{\circ}$ da Constituição Federal, precisava assim, de uma política de assistência estudantil que garantisse esse direito social na universidade. Em meio a isso, decorrente desses posicionamentos mais atenciosos em relação à assistência estudantil, a implantação do Programa Nacional de Assistência Estudantil (PNAES) representou um marco histórico na área após anos de reivindicações de diversos movimentos sociais, em consonância a essas determinações, a UFPA por meio do Programa Permanência, apresenta o objetivo de atender e selecionar estudantes de cursos de graduação em situação de vulnerabilidade socioeconômica, proporcionando condições básicas e assegurando aos estudantes os meios necessários ao pleno desempenho acadêmico, haja vista que prevenindo e erradicando a retenção e a evasão acadêmica, quando decorrentes de dificuldades socioeconômicas e emocionais. Portanto, este trabalho tem o objetivo de apresentar a análise de dados quantitativos deste programa no ano de 2015, para reflexão da dimensão, alcance e consolidação do Programa Assistencial Permanência, assim como refletir o caráter desta política que se desenvolve na UFPA, por meio de pesquisa bibliográfica e documental através de estudos de relatórios institucionais e técnicos, documentos, editais, relatos, instruções normativas, entre outros, assim como por intermédio de estudo do Sistema Gerencial de Assistência EstudantilSigaest, no qual gerencia todos os auxílios assistenciais da universidade.

Palavras-chave: Programa Permanência, UFPA, Assistência Estudantil.

\begin{abstract}
From the 80, the question of the permanence of the university began to be discussed more effervescence, therefore, understood as a social right based on Art. 6 of the Federal Constitution, needed so a student assistance policy to guarantee that social rights at the University. Through it, arising from those more attentive positions in relation to student assistance, the implementation of the Programa Nacional de Assistência Estudantil (PNAES) represented a landmark in the area after years of claims of various social movements, in line with these provisions, the UFPA through Programa Permanência has the objective to meet and select

\footnotetext{
${ }^{1}$ UFPA; Especialista em Políticas Públicas e Serviço Social; Assistente Social da Diretoria de Assistência e Integração Estudantil (DAIE/PROEX/UFPA); Discente do curso de Mestrado em Serviço Social do Programa de Pós-Graduação de Serviço Social-UFPA, ellana@ufpa.br.
} 
undergraduate courses in socioeconomic vulnerability, providing basic conditions and ensuring students the means necessary for the full academic performance, in view of preventing and eradicating the retention and academic evasion when resulting from socio-economic and emotional difficulties. Therefore, this paper aims to present the quantitative data analysis of this program in 2015, to reflect the size, scope and consolidation of the Assistance Program Permanence, and reflect the character of this policy that develops in UFPA through bibliographical and documentary research through institutional reports and technical studies, documents, notices, reports, regulatory instructions, among others, as well as through study Management Sistema Gerencial de Assistência Estudantil-Sigaest, which manages all welfare assistance from the university.

Keywords: Programa Permanência, UFPA, Student Assistance.

\section{Introdução}

O grande Programa Permanência, programa de assistência estudantil de maior porte na UFPA, que apresenta o objetivo de atender e selecionar estudantes de cursos de graduação em situação de vulnerabilidade socioeconômica, cursando a primeira graduação e que não possuem condições de arcar com custeio total ou parcial com alimentação, moradia, material didático-pedagógico e transporte até a universidade, promovendo o apoio à permanência deste estudante na universidade, assim como garantir a igualdade de oportunidades aos estudantes na perspectiva do direito social, proporcionando condições básicas e assegurando aos estudantes os meios necessários ao pleno desempenho acadêmico. Este olhar de atenção aos estudantes, em tese, contribui para melhoria do sistema universitário, prevenindo e erradicando a retenção e a evasão acadêmica, quando decorrentes de dificuldades socioeconômicas e emocionais.

O Programa Permanência desenvolvido na DAIE/PROEX apresenta 12 modalidades de auxílios: Auxílio Permanência e Moradia; Auxílio Permanência e Moradia Intervalar; Auxílio Permanência Especial (PcD); Auxílio Creche; Auxílio Estudante Estrangeiro; Auxílio Emergencial; Auxílio Kit Acadêmico; Auxílio Kit Acadêmico Especial (PcD); Auxílio Instruir; Auxílio Casa do Estudante; PROLÍNGUAS ou Auxílio Acesso às Línguas Estrangeiras, Bolsa de Apoio à Atividade Acadêmica (I e II).

Estas modalidades de auxílios com base em critérios socioeconômicos apoiam os estudantes por meio do recebimento de benefício financeiro, oportunizando a permanência do estudante durante o tempo regular do seu curso até sua diplomação. Os números de auxílios 
disponíveis são previstos de acordo com os recursos disponíveis de assistência estudantil a cada ano, podendo ser ampliados ou retraídos. Contudo, os estudantes selecionados comprometem-se a cumprir com as atividades acadêmicas das disciplinas ao longo de seu curso de graduação, visando a sua diplomação dentro do prazo previsto para a sua integralização curricular, assim como manter-se matriculado durante todo o período de gozo do auxílio.

Os discentes contemplados com os auxílios terão seus desempenhos acadêmicos avaliado em todas as etapas de vigência do auxílio, e deverão obter um bom Coeficiente de Rendimento (CR) para continuar recebendo o auxílio, sendo a avaliação do desempenho acadêmico realizada semestral e anualmente.

O aluno deverá utilizar o valor recebido com despesas de acordo com o objetivo do programa permanência, e caso os requisitos e compromissos estabelecidos em edital não sejam devidamente cumpridos, o discente poderá ter seu auxílio cancelado e também, se comprovada má fé na utilização dos valores, poderá devolver à UFPA o valor recebido indevidamente.

\section{Objetivos/ Metodologia}

Este trabalho tem o objetivo de apresentar a análise de dados quantitativos do auxílio Permanência e Moradia do Programa Permanência no ano de 2015, auxílios com a maior demanda em toda a universidade para reflexão da dimensão, alcance e consolidação do Programa Assistencial Permanência na UFPA, e também refletir sobre o caráter desta política que se desenvolve na universidade. Os dados foram obtidos na forma de pesquisa documental e do estudo do Sistema Gerencial de Assistência Estudantil-Sigaest, no qual gerencia todos os auxílios assistenciais da universidade.

\section{Resultados}

No ano de 2015 o Programa Permanência da UFPA em suas 12 modalidades de auxílios obteve cerca de 6.000 discentes inscritos, somente a modalidade permanência e moradia do Programa Permanência obteve 5.177 inscritos. Em relação ao ano de 2014, os dados provenientes de 2015 elevaram-se em todos os auxílios, visto que se inscreveram no Programa Permanência 5.671 discentes, e somente na modalidade permanência e moradia, houve 4.057 inscrições. 
Segundo o edital norteador do processo seletivo dos auxílios permanência e moradia, esta seleção é realizada por intermédio de procedimentos de análise socioeconômica (análise da renda familiar per capita, análise da situação de moradia (com/sem a família) e análise da forma de ingresso), visita domiciliar (a fim de verificar in loco a realidade socioeconômica e familiar do discente, para comprovação e autenticidade das informações constantes no questionário socioeconômico e da documentação apresentada) e a entrevista que será realizada quando necessária, tendo em vista a necessidade de esclarecimento de situações específicas identificadas pela equipe técnica da DAIE/PROEX, responsável pela triagem e seleção dos discentes.

No Programa Permanência 2015 nas modalidades permanência e moradia obtiveram 5.177 discentes inscritos. Desses, 2.522 eram alunos que solicitavam os auxílios pela primeira vez e os demais eram da modalidade de renovação do auxílio. Neste processo seletivo de 2015, 493 discentes se declararam da cor preta, 2.829 da cor parda, 488 da cor branca, 59 amarela e 7 de origem indígena.

Em sua maioria, eram do sexo feminino (2.360 inscritas) onde os campi com mais participação foram os de Belém (1.398), seguido de Abaetetuba (605 inscritos), Castanhal (483 inscritos), Cametá (430 inscritos), Bragança (333 inscritos), Tucuruí (273 inscritos) e Breves (110 inscritos). No processo seletivo de 2014, estas considerações apresentaram igual proporção ao ano de 2015 em relação à declaração da cor e campi de participação.

O curso com mais participação no processo seletivo do Programa Permanência 2015 nas modalidades permanência e moradia, foi o curso de Pedagogia do campus de Abaetetuba com 128 inscritos, em 2014 este curso alcançou a terceira colocação de participação, precedidos do curso de Pedagogia do campus de Belém (136 inscritos) e Serviço Social do campus de Belém (113 inscritos).

A forma de ingresso por cotas (estudante oriundo de escola pública e/ou cor preta) foi a mais declarada pelos discentes inscritos no programa em 2015, com 2.428 sinalizações, seleção diferenciada para quilombolas (36 inscrições), povos indígenas (4 inscrições) e reserva de vagas $\mathrm{PcD}$ (10 inscrições).

A renda per capita de 152 reais a 203 reais foi a mais relatada, com a quantidade de 654 inscrições, seguida de 254 reais a 305 reais (553 inscrições) e de 203 reais a 254 reais (519 inscrições).

\section{Conclusões}


De acordo com os objetivos propostos em consonância com PNAES, de democratizar as condições de permanência na educação superior pública federal e reduzir as taxas de retenção e evasão contribuindo para a conclusão do ensino superior com êxito, o Programa Permanência de modo geral pode ser considerado uma política social à medida que se caracteriza como uma forma de proteção socioeconômica direcionado aos discentes de baixa renda da UFPA, visto que ela surge, assim como grande parte das políticas públicas brasileiras, decorrentes do reconhecimento da desigualdade social presente em nossa sociedade que influenciam de modo direto e indireto no acesso e permanência dos estudantes no ensino superior, concedendo aos cidadãos, elementos que proporcionam maior proteção e autonomia fruto de reivindicações sociais.

Behring (2000, p.16) a respeito destes indicativos chama atenção para o simplismo das análises bipolares. Essas abordagens desdobram-se na hipótese do engodo, “embebida de economicismo, pela qual a política social é apenas um requisito da acumulação, sendo útil também para a cooptação política dos trabalhadores" e a hipótese da conquista, "embebida de politicismo, onde a política social é um troféu dos trabalhadores, resultado de sua pressão sobre o Estado capitalista”

Essas perspectivas em si, não são equivocadas, entretanto tomando como homogêneas, "ou uma coisa ou outra" não são suficientes na exploração das contradições que são inerentes aos processos sociais que estão presentes cotidianamente na vida dos indivíduos, seja no âmbito econômico, político, social ou cultural.

Na tradição teórica que vem de Marx, é necessária a atenção em considerações de aspectos e semelhanças superficiais presentes nas relações, não se deve perde-se nesta teia de aparente realidade, por isso, a investigação de perspectiva marxista tem como objetivo se aproximar da essência dos fenômenos. E é nesta perspectiva que as análises e interpretações do Programa Permanência estão propostas a considerar, na medida em que a essência não se dá imediatamente, visto que as políticas não podem ser analisadas somente a partir de sua expressão aparente e como algo isolado, precisam, portanto, serem incorporadas à expressão contraditória da realidade que segundo Behring (2011) é a unidade dialética do fenômeno e da essência.

A análise das políticas como resultantes e produtoras de relações complexas e contraditórias estabelecidas entre a sociedade e o Estado, recusa a utilização de perspectivas unilaterais, restritas, simplistas. Assim, na perspectiva crítico-dialética é posto como objetivo o desvelamento da essência dos fenômenos e situa-los na realidade social sob o ponto de vista 
da totalidade que compreende a realidade mostrando-se "nas suas íntimas e complexas determinações, e revela, sob a superfície dos fenômenos, suas conexões internas, necessárias a sua apreensão" (BEHRING,2011, p.40).

Portanto, embora o discurso institucional que envolve a política de assistência estudantil apontar em direção da inclusão social pela educação, da redução das desigualdades sociais e regionais, e conclusão do ensino superior com êxito como objetivos fundantes, a política apresenta um forte apelo ao mecanismo assistencial e paliativo, que mantém o indivíduo na condição de assistido, beneficiário ou favorecido por meio de um processo seletivo e dispêndios de auxílios financeiros que em quantidade, não há para todos que necessitam. O discente não é visualizado como usuário detentor de direitos conquistados, cidadão consumidor e gestor de um serviço a que tem direito.

Esta débil intervenção do estado em políticas sociais fazendo parte delas a assistência estudantil, não emanou de uma natureza predefinida do Estado, foi segundo Behring (2011) criada e apoiada pelos defensores do liberalismo econômico em meio a fortes disputas, onde se defendia o Estado mínimo e não interventivo nas relações de trabalho e comerciais, nem tão preocupado no atendimento às necessidades sociais, no entanto, deveria intervir na garantia de uma relação comercial livre, de interesses liberais.

Vale ressaltar que "Estado mínimo" não é a "diminuição" do Estado, mas sim a diminuição das funções estatais coesivas, de resposta à satisfação de direitos, "Estado mínimo para o trabalho e máximo para o capital” (NETTO e BRAZ, 2006, p.239).

Portanto, é a presença deste mecanismo assistencial em meio aos processos políticos liberais nas políticas sociais, que a configuram como compensatórias de carências, justificando, portanto, a atuação do Estado na perspectiva de seleção do grau de carência em que um indivíduo, família ou grupo social se encontra (seja ela financeira, nutricional, física, etc.) para que seja incluída ou excluída de um determinado programa, projeto ou auxílio social (SPOSATI et al,2010). O elemento assistencial é uma forma de caracterizar a exclusão com face à inclusão pela pseudo benevolência do Estado frente à "carência dos indivíduos".

Com isso, atestar o "grau de carência", "grau de vulnerabilidade" "grau de pobreza" determinados basicamente por triagens socioeconômicas, passa ser a principal preocupação que ratifica o ingresso do indivíduo dentre o aparato das exigências institucionais.

Assim, pode-se refletir quais os elementos que estão presentes na política de assistência estudantil na UFPA, representado pelo grande Programa Permanência. Este é tomado por um viés fragmentador e seletivo, afinal, a assistência ao estudante na UFPA é 
materializada pela concessão de auxílios que são disputados ponto a ponto por meio de um processo seletivo, que põe a prova o grau de pobreza, privação e vulnerabilidades que os estudantes estão expostos, sendo tais elementos identificados e mensurados de acordo com características que "descontrói a construção histórica" do "direito a ter direitos".

A política apresenta o princípio da seletividade que se sobrepõe ao da universalização, seguindo critérios clientelísticos e burocráticos, no qual é reforçado pela perspectiva focalizadora que termina por criar o que Sposati (2010) conceitua de "inclusão excludente" onde há o reconhecimento do indivíduo como sujeito de direito, no momento em que ele é incluído em serviços públicos e programas assistenciais, mas o excluí a partir que de gera naquele um não-reconhecimento de si enquanto cidadão, pois passa a ser identificado e reconhecido pelo seu grau de necessidade dos serviços e programas, a partir da pontuação que adquiriu na somatória dos quesitos relativo às vulnerabilidades e privações.

O assistencial termina por diluir as obrigações e responsabilidades do Estado em garantir os direitos dos cidadãos em simples ações pontuais fragmentadas marcadas pela focalização em prol dos "fracos e pobres".

Portanto em análise, o programa assistencial da UFPA: Programa Permanência, é capaz de ser compreendido como uma política social, baseada nos termos a que se segue este raciocínio.

\section{Referências}

BEHRING, Elaine Rossetti. Fundamentos de Política Social In: Abordagens da Política Social e da Cidadania, no Módulo 3 - Política Social - do Programa de Capacitação Continuada para Assistentes Sociais, Departamento de Serviço Social da UnB, 2000. Disponível em: < http://www.fnepas.org.br/pdf/servico_social_saude/texto1-1.pdf>. Acesso em 25 de junho de 2015.

BEHRING, Elaine Rossetti e BOSCHETTI, Ivanete. Política Social: fundamentos e história. 9a Edição.v2. São Paulo: Cortez, 2011.

NETTO, José Paulo; BRAZ, Marcelo. Economia Política: uma introdução crítica. São Paulo: Cortez, 2006.

SPOSATI, A., YASBEK, MC., FALCÃO MC., BONETTI, D. A assistência na trajetória das políticas sociais brasileiras: uma questão em análise. Editora Cortez. $11^{\mathrm{a}}$ edição. São Paulo. 2010. 
